\title{
EVOLUÇÃO DA EDUCAÇÃO A DISTÂNCIA NO BRASIL E A IMPORTÂNCIA DAS METODOLOGIAS ATIVAS NA MEDIAÇÂO PEDAGÓGICA
}

\author{
DEVELOPMENT OF DISTANCE EDUCATION IN BRAZIL AND THE IMPORTANCE OF ACTIVE \\ METHODOLOGIES IN PEDAGOGICAL MEDIATION \\ DESARROLLO DE LA EDUCACIÓN A DISTANCIA EN BRASIL Y LA IMPORTANCIA DE LAS METODOLOGÍAS \\ ACTIVAS EN LA MEDIACIÓN PEDAGÓGICA \\ Neide Pena ${ }^{1}$, Andreza Lima Rocha Soares ${ }^{2}$
}

Submetido em: 24/11/2019

Avaliado em: 24/04/2020

Aprovado em: 23/02/2021

\section{RESUMO}

Esta pesquisa é parte da Dissertação de Mestrado em Educação, defendida em meados de 2019, em que se buscou compreender a educação a distância (EaD) como uma modalidade educacional de ensino e aprendizagem, em forte expansão no Brasil graças à incorporação de tecnologias digitais de informação e comunicação. Neste trabalho as metodologias ativas são tomadas como uma estratégia e possibilidade de diminuir a evasão no nível superior. A metodologia adotada é de caráter qualitativo, cunho exploratório e descritivo, e se deu por meio da pesquisa documental e bibliográfica sistematizada. Observa-se que o ensino a distância se tornou uma alternativa para muitos estudantes, principalmente para os que trabalham e estudam, entretanto, pode-se ressaltar que as instituições de ensino precisam enfrentar os desafios de combater o índice de evasão, para que ela possa realmente ser um instrumento de democratização de educação superior no pais.

PALAVRAS-CHAVE: : Educação a Distância. Ensino Superior. Metodologias Ativas.

\section{ABSTRACT}

This research is a part of the Master's Dissertation in Education, defended in mid-2019, which sought to understand distance education (DE) as an educational modality of teaching and learning, expanding in Brazil thanks to the incorporation of digital technologies of information and communication. In this work, the active methodologies are taken as a strategy and possibility to reduce dropout at the higher level. The methodology adopted is of qualitative character, exploratory and descriptive nature, and was made through the documental and bibliographic research systematized. It is observed that distance education has become an alternative for many students, especially those who work and study, however, it can be emphasized that educational institutions need to face the challenges of combating dropout rate, so that it can really be an instrument of democratization of higher education in the country.

KEYWORDS: Distance Education. University education. Active Methodologies.

\footnotetext{
${ }^{1}$ Doutora em Educação: Currículo (PUC/SP); Mestrado em Linguística; Especialização em Gestão Educacional; Graduação em Pedagogia. Atualmente é docente e Coordenadora Adjunta do Programa de Pós-Graduação em Educação, Conhecimento e Sociedade (PPGEDUCS) da Universidade do Vale do Sapucaí. Correio eletrônico: neideunivas@gmail.com

${ }^{2}$ Mestrado em Educação (Univás); Graduação em Administração; Especialização em Administração Pública; Especialização em Psicopedagogia; Docente dos Cursos de Administração e Ciências Contábeis na Univás. Correio eletrônico: andrezalsr@gmail.com
} 


\section{RESUMEN}

Esta investigación es una parte de la disertación de maestría en educación, defendida a mediados de 2019, que buscaba entender la educación a distancia (ED) como una modalidad educativa de enseñanza y aprendizaje, expandiéndose en Brasil gracias a la incorporación de tecnologías digitales. de información y comunicación. En este trabajo, las metodologías activas se toman como una estrategia y posibilidad de reducir la deserción en el nivel superior. La metodología adoptada es de carácter cualitativo, exploratorio y descriptivo, y se realizó a través de la investigación documental y bibliográfica sistematizada. Se observa que la educación a distancia se ha convertido en una alternativa para muchos estudiantes, especialmente aquellos que trabajan y estudian, sin embargo, se puede enfatizar que las instituciones educativas deben enfrentar los desafíos de combatir la tasa de deserción, para que pueda Ser realmente un instrumento de democratización de la educación superior en el país.

PALABRAS CLAVE: Educación a distancia. Enseñanza superior. Metodologías activas. 


\section{CONSIDERAÇÕES INICIAIS}

Esta pesquisa é parte integrante da Dissertação de Mestrado em Educação, defendida em meados de 2019. Buscou-se compreender a educação a distância (EaD) como uma modalidade educacional de ensino e aprendizagem, evidenciando que a sua expansão no Brasil tem se dado com a incorporação de tecnologias digitais de informação e comunicação (TDIC). Isso tem permitido alterar as relações entre professor, tutor e o aluno em ambientes físicos diferentes e separados, mas, ao mesmo tempo conectados, pautando-se em formas de aprender e ensinar distintas do modelo tradicional.

Atualmente, o ensino a distância no Brasil passa por um momento de grande expansão com números que ultrapassam a um milhão de alunos matriculados nessa modalidade e a tendência é que esse número cresça cada vez mais, como revelado nos dados do Censo Educacional, publicado em 2018. Pela primeira vez no país, as vagas oferecidas em cursos de graduação na modalidade EaD ultrapassaram as vagas do modelo presencial. Entretanto, este avanço na procura tem sido ofuscado pelo alto índice de evasão que chegou, conforme o Censo Educacional publicado em 2017 a 76\%.

Cabe ainda observar que, ao longo da última década (2008-2017), conforme dados evidenciados da dissertação, a média se manteve em $69,97 \%$. A maioria das grandes instituições de ensino estão apostando nesse mercado, bem como pequenos produtores individuais de conteúdo e materiais didáticos. Cada vez mais os empresários educacionais estão criando seus próprios cursos, investindo em cursos livres e pós-graduação, propondo novas estratégias de trabalhar a educação online e também novas formas de se relacionar com os alunos e o conhecimento.

Entretanto, no cenário da EaD, a "evasão" tem sido considerada um dos principais impasses, que é a desistência do curso pelo aluno antes da conclusão, que se prorroga ao longo dos anos, sendo considerada por especialistas da área, bem como pela Associação Brasileira da Educação a Distância (ABED), como o grande desafio dessa modalidade de ensino.

Vários são os fatores citados no meio midiático como impulsionadores da evasão. Dentre eles, podemos citar: expansão e facilidade de acesso à internet, fator econômico, flexibilidade, menor desconfiança, tecnologia, possibilitando aulas mais interativas. Tais fatores estão impulsionando o crescimento do ensino a distância no Brasil, mas por outro lado, vários fatores também têm impulsionado a evasão, tais como: não atendimento às expectativas, falta de uma comunicação bastante clara e sincera com os alunos no momento da atração, consumidores insatisfeitos com serviços recebidos, falta de conexão do aluno com o curso, interação inadequada entre alunos e professores que agora são mais exigentes, dificuldades com plataformas, falta de apoio e interação institucional.

Pode-se observar que o EaD possui uma dinâmica bem diferente de um curso presencial e, muitas vezes, é tratada sem dar atenção a esses detalhes, como é caso das metodologias adotadas nos diversos cursos, com adaptações ao modelo tradicional presencial. Esse fator, já apontado como problema, também nos cursos presenciais, ganha centralidade na modalidade educacional $\mathrm{EaD}$, com enfoque nas metodologias ativas e nas tecnologias da comunicação e informação.

Neste artigo, as metodologias ativas são tomadas como uma estratégia e possibilidade de diminuir a taxa de evasão nos cursos da modalidade $\mathrm{EaD}$, sendo considerado como conceito de evasão o abandono completo do curso, após a matrícula, independente se chegou ou não a cursar alguma aula (MEC, 2019). Assim, o texto apresenta um comparativo entre ensino presencial e ensino a distância, envolvendo o número de instituições, alunos inscritos, matriculados, egressos, concluintes, evasão escolar e o Ensino Superior a partir de sua institucionalização e a trajetória da EaD no Brasil.

A metodologia adotada é de caráter qualitativo, cunho exploratório e descritivo, e se deu por meio da pesquisa documental e bibliográfica sistematizada. A análise documental envolve levantamento de dados da última década do Censo Educacional (2008-2017) e análise de atos legais que regulamentam o Ensino Superior Presencial e a Distância, além das informações em relatórios periódicos do MEC. $O$ estudo bibliográfico levou em consideração aspectos legais e históricos do EaD, desde a sua origem, sendo tratadas como "Gerações do EaD".

Procuramos refletir sobre as seguintes questões: até que ponto a prática de metodologias ativas pode contribuir para a manutenção e permanência dos estudantes, contribuindo assim para diminuir a evasão no ensino superior?

O objetivo é identificar nas chamadas metodologias 
ativas elementos que substanciem potenciais de fixação dos estudantes nos cursos, seja via tecnologias, ou seja, via mudanças nas relações educativas entre os sujeitos envolvidos na modalidade EaD de forma a poder contribuir para reduzir a evasão.

O texto encontra-se estruturado em três partes, além da introdução e das considerações finais, apresentando aspectos teóricos da educação superior e da modalidade educacional EaD, Histórico do EaD em gerações, modelos de EaD.

\section{ASPECTOS TEÓRICOS RELATIVOS À MODALIDA- DE EaD}

As primeiras experiências na modalidade de ensino a distância ocorreram de forma isolada. Com o tempo esta forma de ensino e aprendizagem ganhou forças e 0 seu desenvolvimento ocorreu por todos os lugares até a segunda metade do século XIX, como relatado por Peters (2012). O crescimento sucedeu nos últimos 25 anos com o início das universidades abertas e a criação das universidades virtuais, se expandindo na maioria das universidades do mundo todo: "[...] seu custo-benefício relativo será decisivo neste processo, especialmente nos países 'em desenvolvimento"' (PETERS, 2012, p. 69). Desde então, a EaD vem sendo discutida em razão do seu amplo alargamento no Brasil.

Em relação à demanda pelo curso superior em EaD, observa-se um aumento de $17,6 \%$ de 2016 para 2017, com base nas informações do Censo Educacional (2017). Os estudantes da modalidade EaD chegaram a quase 1,8 milhão em 2017 , o equivalente a $21,2 \%$ do total de matrículas em todo o ensino superior. As informações divulgadas pelo Censo Educacional são evidentes e mostram seu desenvolvimento anual, principalmente nos últimos anos. Diante do exposto, compreendemos importante abordar sobre a expansão do ensino superior como um todo, caracterizando o cenário que traz demandas cada vez mais diversificadas.

Compreende-se que a modalidade de ensino EaD tem seu histórico e a sua regulamentação é permeada por um complexo emaranhado de legislações ou atos legais que dificultam uma descrição do percurso linear da instituição desta modalidade de ensino no Brasil.

Falar sobre a modalidade educacional EaD no Brasil implica no entendimento sobre as principais diretrizes e a compreensão do contexto em que vem se dando a sua expansão. As normativas que fundamentam a modalidade de ensino EaD se norteiam pela Lei $n^{\circ}$ 9.394, de 20 de dezembro de 1996 (LDB), a qual estabelece as Diretrizes e Bases da Educação nacional, e a legislação específica desta modalidade de ensino, o Decreto $n^{\circ}$ 9.057, de 25 de maio de 2017. Conforme rege o Decreto $n^{\circ} 9.057$ (2017), a educação brasileira, em todas as suas modalidades, está submetida ao processo de regulamentação e avaliação do Sinaes, de acordo com a Lei № 10.861, de 2004 e suas atualizações. Considerando que essa modalidade de educação se insere no contexto da Educação Superior, é preciso destacar também o Decreto № 9.235/2017, que dispõe sobre o exercício das funções de regulação, supervisão e avaliação das instituições de educação superior e dos cursos superiores de graduação e de pós-graduação no sistema federal de ensino.

\section{HISTÓRICO DO EaD EM GERAÇÕES}

De acordo com Peters (2009) as primeiras iniciativas em Educação a Distância foram singulares e isoladas apesar de muitos considerarem que a Educação a Distância é uma metodologia de ensino recente. Segundo Gouvêa e Oliveira (2006) esse tipo de ensino teve início com as epístolas de São Paulo no século I, mas foi na metade do século XIX que ocorreu o ápice da $\mathrm{EaD}$ em todo o mundo. Com descreve Maia e Mattar (2007), foi na metade do século XIX que surge de fato a Educação a Distância motivada pelo desenvolvimento da comunicação e dos meios de transportes. Para compreender a trajetória histórica do EaD passamos a apresentar sobre as gerações pedagógicas do $\mathrm{EaD}$ e as gerações históricas.

\subsection{Gerações Pedagógicas}

Mattar (2012) descreve a trajetória do EaD considerando três gerações da pedagogia do EaD: a) Behaviorista - Cognitivismo, b) Socioconstrutivismo e c) O conectivismo. Entretanto essas três pedagogias descritas por Mattar (2012), se baseiam em estudos realizados nas teorias de Anderson e Dron (2012), nos quais podemos compreender tais pedagogias. 


\section{a) Behaviorista-Cognitivismo}

A Pedagogia Behaviorista-Cognitivista, consolidada na metade do século $X X$, tem o objetivo de aprendizagem vinculado ao comportamento, buscados por meio da utilização de treinamentos. Ideias que se destacaram pelos teóricos Edward Watsonm John Thorndike e Burrhus F. Skinner, nos quais desenvolveram o Design Instrucional e Instructional System Design (ISD) (MATTAR, 2012). Esta teoria, segundo Anderson e Dron (2012, p. 3):

[...] começa com noções de aprendizagem que são geralmente definidas como novos comportamentos ou mudanças em comportamentos que se adquirem como resposta de um indivíduo a estímulos. Deve-se notar nesta definição o foco no indivíduo e na necessidade de medir comportamentos efetivos, e não atitudes ou capacidade.

Com base na teoria c Mattar (2012, p. 18) enfatiza a teoria cognitivista, afirmando que no final da década de 1950, os padrões voltavam-se às "funções e nas operações do cérebro e no modo pelo qual os modelos computacionais eram utilizados para descrever e testar a aprendizagem e o pensamento" (2012, p. 18). Para o autor, dava-se ênfase ao enfoque comportamental, instrucionista, que considerava o indivíduo sujeito às contingências do meio e o conhecimento como uma cópia dada a partir do mundo externo. Ele explica que essa teoria behaviorista - cognitivismo avançou no campo da EaD, utilizando a tecnologia disponível para comunicação para muitos. Mattar (2012, p. 19) destaca que a utilização deste modelo tem como foco "a aprendizagem individual, com liberdade para o aluno seguir seu ritmo e com a presença da docência praticamente reduzida à produção de conteúdo e avaliação".

Nesse mesmo sentido, Anderson e Dron (2012) teorizam que os processos cognitivos proporcionam a motivação e estimulam os interesses dos alunos a adquirirem conhecimentos e esses modelos cognitivo-behavioristas, por meio da utilização de ISD, pelo qual interagem a existência da aprendizagem do aluno e o seu contexto de estudo. Mattar (2012, p. 22) conclui que a Pedagogia Behaviorismo objetiva a aprendizagem através de treinamentos por meio de tutor, designer ins- trucional, por meio de pré-Web, em que se considera um para um e um para muitos com seu resultado voltado para o ensino.

\section{b) Socioconstrutivismo}

A pedagogia socioconstrutivista conceitua-se em Jean Piaget, Vygostsky e Dewey. Anderson e Dron (2012) definem, com base em que o pensamento cognitivo-construtivista retrata uma concepção da construção individual dos conhecimentos, no contexto de Vygostsky e Dewey retrata para o construtivismo social.

$\mathrm{Na}$ concepção de Mattar (2012), socioconstrutivismo do EaD, com base nos autores Jean Piaget, Vygostsky e Dewey, veio a ampliar as possibilidades de tecnologias de comunicação. Para Anderson e Dron (2012, p. 6).

A pedagogia socioconstrutivista reconhece a natureza social do conhecimento e de sua criação na mente dos aprendizes individuais. Os professores não se limitam a transmitir conhecimento para ser passivamente consumido pelos alunos, mas, em vez disso, cada aluno constrói meios pelos quais novos conhecimentos são criados e integrados com o conhecimento existente.

Com o surgimento da era das redes e a diversidade de informações disponíveis o que passou a ser explorado por meio de conectividade ao se buscar aprender através de interações no EaD, permitido que os alunos, professores e grupos se comunicassem utilizando diversos meios de aprendizagem, surgindo a Pedagogia Conectivista.

\section{c) Conectivismo}

O meio mais utilizado nessa geração da modalidade a distância é o Ambiente Virtual de Aprendizagem (AVA). Conforme descrito por Mattar (2012), a Pedagogia conectivista compreende a busca das informações pelo indivíduo, não por meios de memorização ou entendimento de um todo, mas a busca de informações de seu interesse. Esta conectividade permite uma interação aberta, na qual todos os envolvidos na aprendizagem interagem para contribuírem nas informações de uma 
forma ampla e aberta, por meio de diversas redes como blogs, Twitter e Webcast multimídias, por meio de textos, áudios ou demais ferramentas. Esta aprendizagem conectivista propõe aos alunos e professores recriarem conteúdos de estudo para estudos futuros que venham a necessitar desses conhecimentos, tornando-se assim teorias de aprendizagem (MATTAR, 2012).

Anderson e Dron (2012, p. 126), afirmam que "a aprendizagem conectivista centra-se na construção e manutenção de conexões em rede que sejam atuais e flexíveis o suficiente para serem aplicadas a problemas existentes e emergentes". Assim o conectivismo faz com que muitos dos problemas possam ser resolvidos por meio das máquinas através das redes conectadas. Os autores definem que os modelos do conectivismo baseiam-se em:

[...] ubiquidade de conexões em rede entre pessoas, artefatos digitais e conteúdo, o que teria sido inconcebível como formas de aprendizagem a distância, se a World Wide Web não estivesse disponível para mediar o processo. Assim, como vimos no caso das gerações anteriores de ensino a distância, a tecnologia desempenhou um papel importante na determinação das pedagogias potenciais que podem ser empregadas (ANDERSON DRON, 2012, p. 127).

Nesta mesma direção Mattar (2012, p. 22) conclui que a pedagogia conectivista objetiva a construção do conhecimento por meio da colaboração através da interação de alunos e professores pela Web e redes.

\subsection{Gerações Históricas do EaD}

A trajetória histórica do Ensino a Distância encontra-se classificada por diversos autores por categorias consideradas "gerações do EaD". Maia e Mattar (2007) as classificam em três gerações, outros autores classificam esta trajetória em cinco gerações, como Hack (2010). Procuramos relacionar a visão de alguns autores e suas definições quanto às gerações, especialmente, em relação às tecnologias por ela utilizadas. Primeiramente, os autores apresentam considerações de como as três gerações por eles foram classificadas. Para esses autores, a primeira geração do EaD foi a dos "cursos por correspondência" surge em meados do século XIX, voltada para a formação em um ensino por correspondência, com envio de materiais através dos correios. Nesse segmento ou nessa modalidade de ensino, diversos cursos se formavam, especialmente os técnicos, mas os cursos universitários ainda sofriam suas resistências.

Segundo Maia e Mattar (2007), a segunda geração foi a de "novas mídias e universidade abertas", na qual, já contavam com a presença e evolução das tecnologias, quando surgem os meios de comunicação como televisão, rádio, fitas de áudio/vídeo e telefone. Assim, passa a ter maior importância para a evolução do $\mathrm{EaD}$ a inserção em 1969 das universidades abertas de ensino a distância. $O$ interesse pela modalidade de ensino se desenvolvia com os diferentes experimentos pedagógicos que propunha novas ferramentas de ensino. Essa possibilidade levou à expansão do $\mathrm{EaD}$, pois foram criadas as universidades abertas a distância por diversos países do mundo.

A terceira geração "EaD on-line" abre espaço para novas visões do sistema educacional, classificando a utilização de ferramentas de ensino, ampliadas pela tecnologia da informação e comunicação, tomando como destaque os videotextos, microcomputador, tecnologia de mídia, hipertexto e redes de computadores. Essas tecnologias ganharam força em 1995, com a chegada da internet, que possibilitou um novo espaço no EaD, o ambiente virtual de aprendizagem. Assim, esse formato de EaD, com a utilização das redes, propõe mudanças no ensino e aprendizagem nessa modalidade de educação em um modelo novo de interação, participação e estratégias de ensino voltado para o aluno.

As três gerações apresentadas por Maia e Mattar (2007) vão ao encontro com as gerações apresentadas por Hack (2010). Entretanto Hack apresenta também a quarta e a quinta geração. Para o autor, a quarta geração de EAD era baseada na comunicação mediada por computador e a quinta geração de EaD refere-se à geração sofisticada, futura, baseada em Taylor (2001).

Sobre a quarta geração, Hack (2010) relata que, nas décadas de 1990, utilizando computadores e internet como as anteriores, com ensinos aplicados por tecnologias que necessitavam de softwares específicos, esta geração tornou-se global. As ferramentas de ensino utilizadas por essa geração eram o correio eletrônico, bancos de dados, bibliotecas eletrônicas, Plataformas 
Virtuais de Ensino e Aprendizagem. Já a quinta geração de EaD, com base em Taylor (2001) refere-se à geração sofisticada, futura, tratada por Hack (2010) como uma geração que estaria veiculada com estudos referentes a Inteligência artificial. Entretanto, para isso, o autor considera necessário que esta quinta geração necessite de equipamentos avançados para concretizarem a aprendizagem.

Para Taylor (2001), a quinta geração do EaD, decorre a partir da quarta geração, buscando recursos por meio a Web e internet, caracterizando em um modelo de desenvolvimento da e-Interface, por meio de seu portal, envolvendo a todos a conectarem com a universidade de um modo participativo e satisfatório. O autor enfatiza esta geração, considerada como "Intelligent Flexible Learning Model's, que é modelo de educação a distância que incorpora o uso de respostas automatizadas no sistemas e bancos de dados de objetos inteligentes no contexto da entrega pela internet (TAYLOR, 2001, p. 10).

O que podemos compreender com esta organização da trajetória do EaD no formato de gerações é que todas as gerações apresentadas estão fundamentadas com as tecnologias, que vêm avançando com a emergência de novas mídias digitais, multimídias, computadores, por meio do uso das TDIC. Isso tem ganhado força e espaço no cenário educacional, especialmente na modalidade de ensino a distância. Isso permite que o processo de ensino e de aprendizagem resulte no conhecimento mútuo por meio da interação entre alunos, professores e tutores, por meio do uso solidificado dessas ferramentas, com base em uma reflexão cada vez mais pautada na qualificação e reconhecimento do $\mathrm{EaD}$ no Brasil.

\section{MODELOS DE EaD}

Há diversas definições ou significados entre o entendimento EaD fortificadas pelos autores que estudam esta modalidade de ensino, Maia e Mattar (2007), define - EaD como uma modalidade de educação, planejada por docentes ou instituições, em que professores, alunos separados espacialmente, utilizando-se das diversas tecnologias de comunicação. Peters (2012, p. 73) retrata estes modelos como propostas de ideias a serem estudadas e implantadas, no despertar de seus interes- ses os considerando como modelos típicos e paradigmáticos". Com base em Peters (2012), os modelos de EaD podem ser explicados como no quadro 1:

\section{Quadro 1: Modelos de EaD}

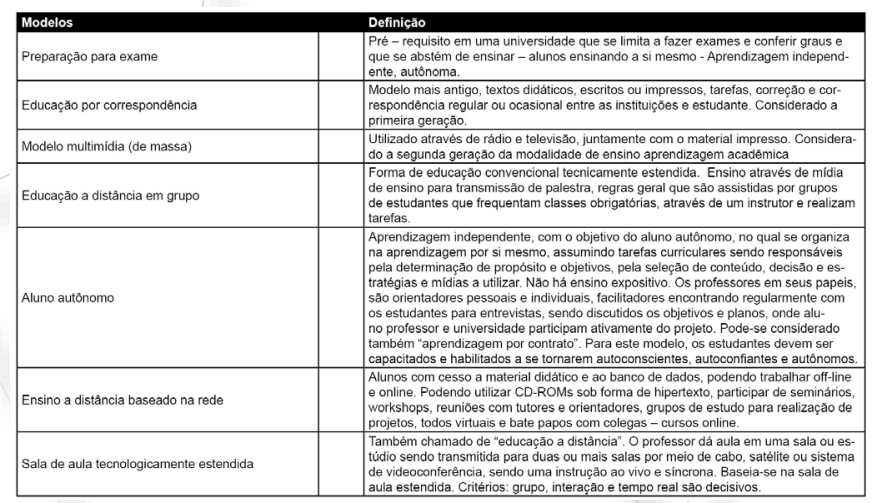

Os modelos apresentados pelo autor, como forma de modelos híbridos, devem ser utilizados de acordo com os fatores, cultural, infraestrutura, tradições de ensino e aprendizagem e dos avanços tecnológicos aos sistemas de educação a distância, bem como as políticas educacionais e institucionais. Peters (2012) enfatiza que, na era das mudanças aceleradas, devem se ter em mente um modelo de uma possível universidade do futuro ao desenvolver novos cursos de ensino a distância e destaca:

A universidade do futuro terá que combinar educação a distância, aprendizagem em um ambiente informatizado e discussões eruditas exaustiva face a face em espaços e aprendizado acadêmico reais que permitam que os estudantes participem do processo científico de criação de conhecimento (PETERS, 2012, p. 83).

O modelo que o autor descreveu em 2012, solidifica nos tempos atuais, porém com seus novos avanços tecnológicos e midiáticos cada vez mais sistematizados, constantes e acelerados. Tecnologias indispensáveis nos cotidianos de qualquer estudante, de qualquer instituição e das matérias pedagógicos presentes e instaurados na perspectiva de ensino, os modelos pedagógicos também são elementos substanciais nas modalidades de ensino a distância.

${ }^{3}$ Intelligent Flexible Learning Model: em português a expressão significa “Modelo de Aprendizado Flexível Inteligente” (tradução livre). 


\section{QUANTITATIVO DO ENSINO SUPERIOR A DISTÂN-} CIA

Relativamente à metodologia adotada na coleta de dados, no primeiro momento, a coleta de dados e informações foi realizada diretamente no site do MEC, com dados dos últimos anos quantificados e tabelados. Em segundo momento e para enriquecimento dos dados, recorremos a outras fontes, no caso, ao site da ABED onde foram coletados dados complementares. Entretanto, é importante ressaltar que, ao comparar os dados de fontes diferentes, verificou-se divergência nos resultados. Diante disso, procedemos a uma terceira rodada de pesquisa que foi realizada por meio de uma exaustiva consulta aos arquivos disponibilizados no portal eletrônico do INEP. Essa busca foi feita separadamente ano a ano do Censo Escolar pelo período de 10 anos, entre 2008 e 2017.

Conforme dados apresentados a seguir, observa-se um índice crescente de expansão da modalidade EaD no ensino superior. A ampliação do EaD em relação ao total de matrículas no ensino superior presencial tem sido apontada como responsável pelo aumento do percentual de matrículas na Educação Superior. A sistematização dos dados de uma década, apresentado no quadro 12, permite visualizar essa expansão do EaD na última década, mas também evidencia um alto índice de alunos que ficam pelo caminho.

Quadro 12 - Alunos Inscritos/matrícula / Egressos/ concluintes nas IES EaD - 2008 a 2017

\begin{tabular}{|c|c|c|c|c|c|c|c|c|c|}
\hline \multicolumn{10}{|c|}{ Número de Inscritos na Educaçäo Superior a Distância } \\
\hline 2008 & 2009 & 2010 & 2011 & 2012 & 2013 & 2014 & 2015 & 2016 & 2017 \\
\hline 708.784 & 677.327 & 1.386 .852 & 797.176 & 1.029 .981 & 1.493 .832 & 2.256 .412 & 1.656 .470 & 2.495 .121 & 3.001 .350 \\
\hline \multicolumn{10}{|c|}{ Números de Matricula no Ensino Superior Educação a Distância } \\
\hline 2008 & 2009 & 2010 & 2011 & 2012 & 2013 & 2014 & 2015 & 2016 & 2017 \\
\hline 727.961 & 838.125 & 930.179 & 992.927 & 1.113 .850 & 1.153 .572 & 1.341 .842 & 1.393 .752 & 1.494 .418 & 1.756 .982 \\
\hline \multicolumn{10}{|c|}{ Número de Ingressos na Educaçäo e Distância } \\
\hline 2008 & 2009 & 2010 & 2011 & 2012 & 2013 & 2014 & 2015 & 2016 & 2017 \\
\hline 430.259 & 332.469 & 380.328 & 431.597 & 542.633 & 515.405 & 727.738 & 727.336 & 888.043 & 1.073 .497 \\
\hline \multicolumn{10}{|c|}{ Números de Concluintes no Ensino Superior Educaçäo a Distância } \\
\hline 2008 & 2009 & 2010 & 2011 & 2012 & 2013 & 2014 & 2015 & 2016 & 2017 \\
\hline 70.068 & 132.269 & 144.553 & 151.552 & 174.322 & 161.072 & 189.788 & 233.704 & 230.717 & 252.163 \\
\hline
\end{tabular}

Fonte: Dados INEP- Elaborado pela autora

Ao considerar dados apresentados é importante salien- tar a preocupação com o alto índice de aluno ingressante e o índice bem menor de concluintes no ensino superior considerando a modalidade presencial e à distância. A relação entre ingressantes e concluintes evidencia o que os autores já apontaram com um dos grandes impasses da EaD, caracterizada "evasão", principalmente quando comparado com os cursos presenciais. Este cenário pode ser observado nos quadros 3 .

Quadro 3 - Evasão - IES Presencial - 2008 a 2017

\begin{tabular}{|r|r|r|r|r|r|r|r|r|r|}
\hline \multicolumn{10}{|c|}{ Evasäo Escolar Educaçäo Presencial\% } \\
\hline $\mathbf{2 0 0 8}$ & $\mathbf{2 0 0 9}$ & $\mathbf{2 0 1 0}$ & $\mathbf{2 0 1 1}$ & $\mathbf{2 0 1 2}$ & $\mathbf{2 0 1 3}$ & $\mathbf{2 0 1 4}$ & $\mathbf{2 0 1 5}$ & $\mathbf{2 0 1 6}$ & $\mathbf{2 0 1 7}$ \\
\hline $\mathbf{5 3 , 1 4 8 3}$ & 53,2728 & 47,8649 & 55,0315 & 60,2582 & 62,742 & 64,63193 & 62,8363 & 64,3407 & 50,6183 \\
\hline
\end{tabular}

Fonte: Dados INEP- Elaborado pela autora

Quadro 4 - Evasão - IES EaD - 2008 a 2017

\begin{tabular}{|r|r|r|r|r|r|r|r|r|r|}
\hline \multicolumn{10}{|c|}{ Evasäo Escolar Educaçäo a Distância\% } \\
\hline 2008 & 2009 & 2010 & 2011 & 2012 & 2013 & 2014 & 2015 & 2016 & 2017 \\
\hline 83,7149 & 60,2161 & 61,99 & 64,8857 & 67,8740 & 68,74800 & 73,9200 & 67,8680 & 74,0200 & 76,5100 \\
\hline
\end{tabular}

Fonte: Dados INEP- Elaborado pela autora

Para compreensão sistematizada dos dados apresentados, foram elaborados os cálculos percentuais, considerando inscritos, matrículas, ingressantes, concluintes e evasão do ensino presencial e a distância. Para calcular o percentual apresentado na última década, efetuou-se a média entre 2008 a 2017 em ambas as modalidades. Os dados encontram-se organizados nos quadros 5 e 6 .

Quadro 5 - Percentual Evolução Ensino Presencial e Média de Evasão - 2008 a 2017

\begin{tabular}{|c|c|c|c|c|}
\hline \multicolumn{5}{|c|}{ Educação Superior Presencial - Últimos 10 anos - } \\
\hline Inscritos & Matrícula & Ingressos & Concluintes & Evasão Escolar \\
\hline $159,66 \%$ & $28,54 \%$ & $41,80 \%$ & $18,40 \%$ & $57,47 \%$ \\
\hline
\end{tabular}

Fonte: Dados INEP- Elaborado pela autora 
Quadro 6 - Percentual Evolução EaD e Média da Evasão - 2008 a 2017

\begin{tabular}{|c|c|c|c|c|}
\hline \multicolumn{5}{|c|}{ Educação a Distância - Últimos 10 anos - } \\
\hline Inscritos & Matricula & Ingressos & Concluintes & Evasão Escolar \\
\hline $323,45 \%$ & $141,36 \%$ & $149,50 \%$ & $259,88 \%$ & $69,97 \%$ \\
& & & & \\
\hline
\end{tabular}

Fonte: Dados INEP- Elaborado pela autora

Como podemos verificar a diferença entre os percentuais é significativa tanto no número de inscritos, de matrículas, de ingressos e concluintes, bem como de evasão escolar. Chama a atenção o alto índice de elevação no que se refere à Educação a Distância em todos os itens, revelando que a demanda pelo EaD é nitidamente mais acelerada. No entanto, não podemos concluir que as condições da conclusão de ensino abordam tal aceleração, devido ao seu alto índice de evasão, comparado com o Ensino Presencial.

Não se pode negar que sem dúvida, houve uma grande evolução do EaD, comparado com o Ensino Superior presencial, mas o cenário instiga à investigação sobre as metodologias utilizadas nesta modalidade de ensino ou sobre a sua organização. Atualmente, por meio da ABED várias discussões vendo sendo realizadas via fóruns e publicações, colocando em discussão o uso de metodologias ativas na EaD como estratégia para diminuir o alto índice de evasão, já comprovado. $\mathrm{Na}$ sequência, apresentamos o que dizem alguns autores e algumas pesquisas

\section{CONSIDERAÇÕES FINAIS}

Diante da expansão dos cursos na modalidade EaD e com a ampla procura e oferta de cursos, de natureza formal e informal, novas necessidades do processo pedagógico desafiam as ações docentes, os métodos de ensino e as próprias estruturas institucionais, entre outros. Nesse cenário, as metodologias ativas têm se apresentado como uma das estratégias mais adequadas e viáveis para atender a essas novas demandas. As metodologias ativas têm sido foco de discussão nos cursos superiores ou cursos técnicos e específicos, no que se refere ao seu potencial de colocar os alunos como principal personagem de seu aprendizado.

É possível considerar que a evolução das tecnolo- gias educacionais e seus usos por professores e alunos estão presentes nas metodologias de ensino presencial e EaD, sendo atualmente condição indispensável no processo de ensino e aprendizagem. Entretanto, o que é preciso considerar é se o envolvimento das tecnologias está contribuindo para tornar a aprendizagem participativa e colaborativa. Foi observado que, no contexto organizacional, há uma diversidade de práticas metodológicas permitindo aos envolvidos, que pretendem continuar sua formação, um processo de trabalho estruturado, com estudos e práticas inovadoras, estágios, cursos livres, palestras, workshops e vivências no próprio local de trabalho, com usos de metodologias variadas, o que possibilita levar a uma qualificação específica e ampla.

Pode-se evidenciar que a tecnologia permite hoje uma integração de todos os espaços e tempos e que o ensinar e aprender acontece numa interligação simbiótica, profunda, constante entre o mundo físico e mundo digital, mas não são suficientes para resolver questões fundamentais da educação, como é caso da evasão. Atualmente outros modelos vêm sendo implementados na tentativa de obter mais interação entre os alunos, docentes e instituição, tornando o espaço de ensino e aprendizagem como um modelo estendido, híbrido, uma sala de aula ampliada, que se mescla, hibridiza constantemente. Como analisa Moran (2015), a educação formal vem se tornando cada vez mais blended, misturada, híbrida, porque não acontece só no espaço físico da sala de aula, mas nos múltiplos espaços do cotidiano, que incluem os digitais.

Com base dos autores visitados, observa-se uma defesa a uma aprendizagem ativa e interativa, realizada por meios tecnológicos eletrônicos e digitais. Entretanto, há um consenso de que as tecnologias não suprem somente a necessidade de construção de saberes e fazeres dos meios tradicionais. Ao contrário, as tecnologias estão presentes na educação frente às necessidades da aprendizagem e devem ser consideradas como inovação e não de substituição ao professor. Observa-se que o ensino a distância se tornou uma alternativa para muitos estudantes, principalmente para os que trabalham e estudam, entretanto, conforme o Censo Educacional, pode-se ressaltar que as instituições de ensino precisam enfrentar os desafios de combater o índice de evasão, para que ela possa realmente ser e/ou representar um instrumento de democratização de educação superior no pais. 


\section{REFERÊNCIAS}

ABED. Associação Brasileira de Educação a Distância. Legislação em EAD. São Paulo, 2017. Disponível em: http://www.abed.org.br/documentos/ArquivoDocumento.440.pdf. Acesso em: 15 nov. 2018.

Censo EAD Brasil: Relatório Analítico da Aprendizagem a Distância no Brasil. São Paulo: Pearson Education do Brasil, 2016. Disponível em: http:// abed.org.br/censoead2016/Censo_EAD_2016_portugues.pdf. Acesso: 08 de set. 2019.

ANDERSON, T.; DRON, J. Três gerações de pedagogia de Educação a Distância. Tradução: João Mattar. EAD em foco: Revista Científica em Educação a Distância, Rio de Janeiro, v. 2, n. 1, p. 129-134, 2012. Disponível em: http://eademfoco.cecierj.edu.br/index.php/Revista/ article/view/162/33. Acesso: 23 nov. 2018.

BRASIL. Lei no 10.861, de 14 de abril de 2004. Institui o Sistema Nacional de Avaliação da Educação Superior SINAES e dá outras providências.

Disponível em: http://www.planalto.gov.br/ccivil_03/_ ato2004-2006/2004/lei//10.861.htm Acesso: 12 ago 2019.

BRASIL e-MEC. Ministério da Educação. Cadastro Nacional de Cursos e Instituições de Educação Superior. 2019. Disponível em: emec.mec.gov.br. Acesso em: 14 nov. 2019.

BRASIL INEP. ORACLE Business Intelligence. 2019. Panorama de IES na Educação Superior. Educação Superior. Disponível em: <https://inepdata.inep.gov.br/ analytics/saw.dll?Portal\&PortalPath=\%2Fshared $\% 2 \mathrm{FE}$ duca $\%$ C3\%A7\%C3\%A30\%20Superior\%20-\%20Acesso $\% 20$ Externo\%2FArquivos $\% 2$ FCenso $\% 2$ FConsolidad ०\%2FInforma\%C3\%A7\%C3\%B5es $\% 20$ Consolidadas $\%$ 2FInstitui\%C3\%A7\%C3\%B5es\%20de\%20Ensino\%20 Superior\%2FPanorama\%20de \%20IES\%20na \%20 Educa\%C3\%A7\%C3\%A30\%20Superior>. Acesso em: 12 maio 2019.

Educação Superior. 2019. Disponível em: <https://inepdata.inep.gov.br/analytics/ saw.dll?Dashboard\&NQUser=inepdata\&NQPas sword $=$ Inep2014\&PortalPath $=\% 2 F$ shared $\% 2 F C$ enso $\% 20$ da $\% 20$ Educa $\%$ C $3 \%$ A $7 \%$ C $3 \%$ A 30 $\% 20$ Superior $\% 20-\% 20$ In ep Dat a $\% 2 \mathrm{~F}$. portal\%2FEduca\%C3\%A7\%C3\%A30\%20Superior>. Acesso em: 23 maio 2019.

HACK, J. R. Linguagem virtual e audiovisual na EAD. 2010. Disponível em: <http://www.hack.cce.prof.ufsc.br/ wp-content/uploads/2013/06/LivroProdMatAutoinstrutivosEADCap03.pdf>. Acesso: 24 nov. 2018.

MAIA, C.; MATTAR, J. ABC da EaD; a educação a distância hoje. 1. ed. São Paulo: Pearson, 2007.

MORÁN, J. Mudando a educação com metodologias ativas. Coleção Mídias Contemporâneas. Convergências Midiáticas, Educação e Cidadania: aproximações jovens, v. 2, n. 1, p. 15-33, 2015.

Disponível em: <http://rh.newwp.unis.edu.br/wp-content/ uploads/sites/67/2016/06/Mudando-a-Educacao-com-Metodologias-Ativas.pdf>. Acesso em: 19 ago. 2019.

Universidades precisam rever os seus modelos pedagógicos. Disponível em: <http://www.ufrgs. $\mathrm{br} /$ nucleoead/documentos/moranUniversidades.htm>. Acesso em: 03 maio 2019.

MATTAR, J. Tutoria e interação em Educação a Distância. 1. ed. São Paulo: Cengage Learning, 2012.

PETERS, O. A educação a distância em transição. São Leopoldo: Unisinos, 2012.

TAYLOR, J. C. $20^{\mathrm{a}}$ conferência mundial do ICDE sobre aprendizagem aberta e educação à distância. ICDE - International Council for Open and Distance Education, 2001. Disponível em: <http://citeseerx.ist.psu. edu/viewdoc/download?doi=10.1.1.580.3906\&rep=rep1 \&type=pdf>. Acesso: 09 set. 2019. 